KLEIST-JAHRBUCH 2003 


\title{
KLEIST-JAHRBUCH 2003
}

\author{
Im Auftrag des Vorstandes \\ der Heinrich-von-Kleist-Gesellschaft \\ herausgegeben von \\ Günter Blamberger \\ (verantwortlich für Kleist-Preis, Jahrestagung 2002, Abhandlungen), \\ Sabine Doering und Klaus Müller-Salget \\ (verantwortlich für Rezensionen)
}




\section{Anschrift der Redaktion:}

Dr. Ingo Breuer, Universität zu Köln, Institut für Deutsche Sprache und Literatur, Albertus-Magnus-Platz, D-50931 Köln, eMail: ingo.breuer@uni-koeln.de Mitarbeit: Pamela Moucha und Dominik Paß

Bibliografische Information Der Deutschen Bibliothek

Die Deutsche Bibliothek verzeichnet diese Publikation in der Deutschen Nationalbibliografie; detaillierte bibliografische Daten sind im Internet über $b t t p: / / d n b$. $d d b$.de abrufbar.

ISBN 978-3-476-01978-3

ISBN 978-3-476-02897-6 (eBook)

DOI 10.1007/978-3-476-02897-6

Dieses Werk einschließlich aller seiner Teile ist urheberrechtlich geschützt.

Jede Verwertung außerhalb der engen Grenzen des Urheberrechtsgesetzes ist ohne Zustimmung des Verlages unzulässig und strafbar. Das gilt insbesondere für Vervielfältigungen,

Übersetzungen, Mikroverfilmungen und die Einspeicherung und Verarbeitung in elektronischen Systemen.

(C) 2003 Springer-Verlag GmbH Deutschland

Ursprünglich erschienen bei J. B. Metzlersche Verlagsbuchhandlung

und Carl Ernst Poeschel Verlag GmbH in Stuttgart 2003

www.metzlerverlag.de

info@metzlerverlag.de 


\section{INHALT}

\section{Verleibung des Kleist-Preises 2002}

Günter Blamberger: Rede zur Verleihung des Kleist-Preises an Martin Mosebach im Berliner Ensemble am 30.11.2002 ............. 3

Brigitte Kronauer: »... ewiger Flügel! Oh!« Laudatio zur Verleihung des Kleist-Preises an Martin Mosebach .................. 6

Martin Mosebach: »Romane schreiben, wie man einen Schuh macht«. Dankrede bei der Verleihung des Kleist-Preises . . . . . . . . . . . . .

\section{Internationale Jabrestagung 2002 in Berlin: \\ ,TRANSFORMATIONEN<}

Hans Jürgen Scheuer: Pferdewechsel - Farbenwechsel. Zur Transformation des adligen Selbstbildes in Kleists >Prinz Friedrich von Homburg‘ ....

Helmut J. Schneider: Der Sohn als Erzeuger. Zum Zusammenhang politischer Genealogie und ästhetischer Kreativität bei Heinrich von Kleist

Bernd Hamacher: »Auf Recht und Sitte halten«? Kreativität und Moralität bei Heinrich von Kleist $\ldots \ldots \ldots \ldots \ldots \ldots \ldots \ldots \ldots \ldots \ldots \ldots \ldots \ldots \ldots \ldots \ldots \ldots \ldots$

Peter Philipp Riedl: Transformationen der Rede. Kreativität und Rhetorik

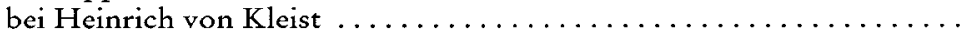

Dominik Paß: Die Beobachtung der allmählichen Verfertigung der Gedanken beim Reden. Eine systemtheoretische Lektüre ............

Rolf-Peter Janz: Mit den Augen Kleists: Caspar David Friedrichs >Mönch

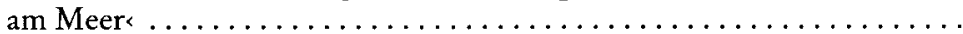

Caroline Pross: Verschobene Anfänge. Bruch und Begründung in Kleists ,Hermannsschlacht $<$, Arnims $>$ Die Vertreibung der Spanier und Brentanos Viktoria und ihre Geschwister..$\ldots \ldots \ldots \ldots \ldots \ldots \ldots \ldots$

Christine Künzel: Gewaltsame Transformationen. Der versehrte weibliche Körper als Text und Zeichen in Kleists $>$ Hermannsschlacht $<. . . \ldots \ldots$ 
Dorothea von Mücke: Metamorphose und Idylle. Entgrenzungsphantasien

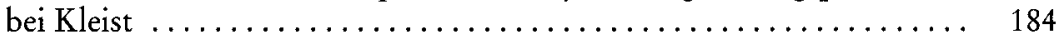

Caroline Neubaur: Penthesilea und die Kategorie des Gräßlichen ....... 199

David Ratmoko: Das Vorbild im Nachbild des Terrors. Eine Untersuchung des gespenstischen Nachlebens von $>$ Michael Kohlhaas...........

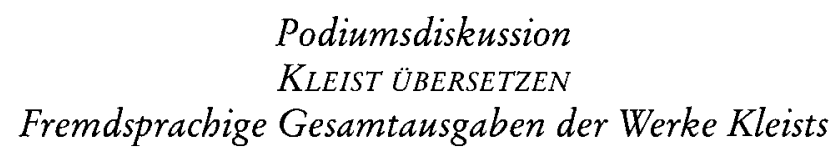

Gabriella Gönczy: Einführung $\ldots \ldots \ldots \ldots \ldots \ldots \ldots \ldots \ldots \ldots \ldots \ldots \ldots \ldots \ldots$

Yoko Tawada: Kleist auf Japanisch $\ldots \ldots \ldots \ldots \ldots \ldots \ldots \ldots \ldots \ldots \ldots, 241$

László F. Földényi: Kleist auf Ungarisch $\ldots \ldots \ldots \ldots \ldots \ldots \ldots \ldots \ldots \ldots \ldots \ldots \ldots$

András Forgách: Übersetzen ins Klassische $\ldots \ldots \ldots \ldots \ldots \ldots \ldots \ldots \ldots .248$

László Márton: Über die Frage, ob es möglich ist, mit einem Toten Freundschaft zu schliessen $\ldots \ldots \ldots \ldots \ldots \ldots \ldots \ldots \ldots \ldots \ldots \ldots \ldots .252$

Pierre Deshusses: Kleist - Das Theater des Schreckens $\ldots \ldots \ldots \ldots \ldots \ldots .256$

\section{Abhandlungen und Miszellen}

Ulrich Fülleborn: Dem Scheitern von Kleists >Robert Guiskard ^nachgefragt 263

Yixu Lü: Zur Schreibtechnik Kleists im `Käthchen von Heilbronn ‘ . . . . . 282

Klaus Müller-Salget: Kleine Funde im Nachlass Paul Hoffmanns . ....... 307 
Klaus Müller-Salget: Das Erlebnis und die Dichtung? (über: Rudolf Loch, Kleist. Eine Biographie, Göttingen 2003) ...................

Hans Richard Brittnacher: Rasse und Geschlecht in Kleists ,Verlobung, (über: Barbara Gribnitz, Schwarzes Mädchen, weißer Fremder. Studien zur Konstruktion von 'Rasse und Geschlecht in Heinrich von Kleists Erzählung >Die Verlobung in St. Domingo<, Würzburg 2002) ........

Sabine Doering: Codierungen der Gewalt - interdisziplinär (über: Christine Künzel, Vergewaltigungslektüren. Zur Codierung sexueller Gewalt in Literatur und Recht, Frankfurt und New York 2003) ............

Anton Philipp Knittel: Patriotischer Kunstkämpfer und poetischer Künstlerfreund (über: Dorothee von Hellermann, Gerhard von Kügelgen (1772-1820). Das zeichnerische und malerische Werk, Berlin 2001) ....

Siglenverzeichnis .................................. 335

Anschriften der Mitarbeiterinnen und Mitarbeiter .............. 336

Informationen zur Heinrich-von-Kleist-Gesellschaft. . . . . . . . . . 338 